\title{
Subtyping Cryptosporidium xiaoi, a Common Pathogen in Sheep and Goats
}

\author{
Yingying Fan ${ }^{1,2,+}$, Xitong Huang ${ }^{1,+}$, Sheng Guo ${ }^{1}$, Fang Yang ${ }^{1}$, Xin Yang ${ }^{3} \mathbb{D}$, Yaqiong Guo ${ }^{1}$, Yaoyu Feng ${ }^{1,2} \mathbb{D}$, \\ Lihua Xiao ${ }^{1,2, *(D)}$ and $\mathrm{Na} \mathrm{Li}^{1,2, *}$ \\ 1 Center for Emerging and Zoonotic Diseases, College of Veterinary Medicine, South China Agricultural \\ University, Guangzhou 510642, China; fanyingying@webmail.hzau.edu.cn (Y.F.); \\ huangxitong2021@163.com (X.H.); guosheng201911@163.com (S.G.); yf1432277601@163.com (F.Y.); \\ guoyq@scau.edu.cn (Y.G.); yyfeng@scau.edu.cn (Y.F.) \\ 2 Guangdong Laboratory for Lingnan Modern Agriculture, Guangzhou 510642, China \\ 3 College of Veterinary Medicine, Northwest A\&F University, Yangling, Xianyang 712100, China; \\ xinyang@nwafu.edu.cn \\ * Correspondence: 1xiao1961@gmail.com (L.X.); nli@scau.edu.cn (N.L.) \\ + These authors contributed to the research equally.
}

check for updates

Citation: Fan, Y.; Huang, X.; Guo, S.; Yang, F.; Yang, X.; Guo, Y.; Feng, Y.; Xiao, L.; Li, N. Subtyping Cryptosporidium xiaoi, a Common Pathogen in Sheep and Goats. Pathogens 2021, 10, 800. https:// doi.org/10.3390/pathogens 10070800

Academic Editor: Luiz Shozo Ozaki

Received: 2 June 2021

Accepted: 22 June 2021

Published: 24 June 2021

Publisher's Note: MDPI stays neutral with regard to jurisdictional claims in published maps and institutional affiliations.

Copyright: (c) 2021 by the authors. Licensee MDPI, Basel, Switzerland. This article is an open access article distributed under the terms and conditions of the Creative Commons Attribution (CC BY) license (https:/ / creativecommons.org/licenses/by/ $4.0 /)$.

\begin{abstract}
Cryptosporidiosis is a significant cause of diarrhea in sheep and goats. Among the over 40 established species of Cryptosporidium, Cryptosporidium xiaoi is one of the dominant species infecting ovine and caprine animals. The lack of subtyping tools makes it impossible to examine the transmission of this pathogen. In the present study, we identified and characterized the $60-\mathrm{kDa}$ glycoprotein (gp60) gene by sequencing the genome of C. xiaoi. The GP60 protein of C. xiaoi had a signal peptide, a furin cleavage site of RSRR, a glycosylphosphatidylinositol anchor, and over 100 O-glycosylation sites. Based on the gp60 sequence, a subtyping tool was developed and used in characterizing C. xiaoi in 355 positive samples from sheep and goats in China. A high sequence heterogeneity was observed in the gp60 gene, with 94 sequence types in 12 subtype families, namely XXIIIa to XXIIIl. Co-infections with multiple subtypes were common in these animals, suggesting that genetic recombination might be responsible for the high diversity within $C$. xiaoi. This was supported by the mosaic sequence patterns among the subtype families. In addition, a potential host adaptation was identified within this species, reflected by the exclusive occurrence of XXIIIa, XXIIIc, XXIIIg, and XXIIIj in goats. This subtyping tool should be useful in studies of the genetic diversity and transmission dynamics of C. xiaoi.
\end{abstract}

Keywords: Cryptosporidium xiaoi; 60-kDa glycoprotein; gp60; subtyping; genetic diversity; host adaptation

\section{Introduction}

Cryptosporidium spp. are important diarrheal pathogens in humans and various animals [1]. Currently, 45 Cryptosporidium species and over 100 genotypes have been recognized [2]. Among them, C. paroum, C. ubiquitum, and C. xiaoi are common species in sheep and goats. C. paroum and C. ubiquitum are zoonotic species that infect a wide range of hosts, while C. xiaoi appears to be adapted to ovine and caprine animals [3]. C. xiaoi, previously known as the $C$. bovis-like genotype, is the most common species in sheep and goats in most areas except Europe [4-8].

Sequence analysis of the $60-\mathrm{kDa}$ glycoprotein ( $g p 60)$ gene has been used extensively in subtyping C. paroum, C. ubiquitum, and other zoonotic species due to its high sequence heterogeneity and relevance to parasite biology. The unique distribution of subtype families and subtypes have significantly improved our understanding of host adaptation and transmission dynamics within these Cryptosporidium spp. [2,9-15]. Recently, gp60 genebased subtyping tools have been developed for molecular epidemiological studies of some non-human pathogenic Cryptosporidium spp., such as the bovine-adapted C. ryanae and the 
marsupial-adapted C. fayeri $[16,17]$. However, such a tool is not available for C. xiaoi, which is occasionally found in humans [18].

In this study, we sequenced the genome of C. xiaoi, identified its gp60 gene, and developed a subtyping tool for genetic characterizations of isolates from sheep and goats.

\section{Materials and Methods}

\subsection{Samples}

DNA extracts from 434 C. xiaoi-positive samples were used in this study, including those from Small Tail Han sheep (Ovis aries), Hu sheep (Ovis aries), Tibetan sheep (Ovis aries), Huanghuai goats (Capra hircus), and Black goats (Capra hircus) on 11 farms in Qinghai, Henan, Anhui, and Guangdong, China (Table 1). The C. xiaoi-positive samples were obtained from previous and ongoing studies of molecular epidemiology of cryptosporidiosis in sheep and goats in China [19]. All the samples were identified as positive for C. xiaoi by PCR and sequence analysis of an $\sim 830$-bp fragment of the small subunit $(S S U)$ rRNA gene [20].

\subsection{Identification of the gp60 Gene of C. xiaoi}

To obtain the nucleotide sequence of the gp60 gene of C. xiaoi, we conducted wholegenome sequencing of one isolate (SCAU2942) from a Hu sheep in Anhui, China using the established procedures [21]. The genome was sequenced using Illumina HiSeq 2500 analysis of an Illumina TruSeq (v3) library with 250-bp paired-end reads. The sequence reads were assembled de novo using the SPAdes version 3.13 (http:/ / cab.spbu.ru/software/ spades/, accessed on 21 November 2019) with a K-mer size of 63. The gp60 gene of C. xiaoi was identified by the blastn analysis of the genome assembly with the gp60 (cgd6_1080) sequence of $C$. parvum. The coding region and amino acid sequence of the gp60 gene were predicted using the combination of FGENESH (http:/ / www.softberry.com/berry.phtml, accessed on 15 December 2019) and blastp search of the NCBI database.

\subsection{Subtyping of C. xiaoi}

Based on the sequence of the C. xiaoi gp60 gene, nested PCR primers were designed for the subtyping analysis. The primers used in primary and secondary PCR were Xiaoi-gp60F1 (5'-CCTCTCGGCACTTATTGCCCT-3') and Xiaoi-gp60-R1 (5'-ATACCTGAGATCAAAT GCTGATGAA- $\left.3^{\prime}\right)$, and Xiaoi-gp60-F2 (5'-CCTCTTAGGGGTTCATTGTCTA-3') and Xiaoigp60-R2 (5'-TACCTTCAAAGATGACATCAC-3'), respectively. Each PCR was performed in a $50 \mu \mathrm{L}$-reaction containing $1 \times \mathrm{PCR}$ master mix (Thermo Scientific, Waltham, MA, USA), $0.25 \mu \mathrm{M}$ primary PCR primers or $0.5 \mu \mathrm{M}$ secondary PCR primers, and $1 \mu \mathrm{L}$ of DNA (primary PCR) or $2 \mu \mathrm{L}$ of the primary PCR product (secondary PCR). To reduce PCR inhibitors, $400 \mathrm{ng} / \mu \mathrm{L}$ of nonacetylated bovine serum albumin (Sigma-Aldrich, St. Louis, MO, USA) was used in the primary PCR. The PCR amplification consisted of an initial denaturation at $94{ }^{\circ} \mathrm{C}$ for $5 \mathrm{~min} ; 35$ cycles of $94{ }^{\circ} \mathrm{C}$ (denaturation) for $45 \mathrm{~s}, 55^{\circ} \mathrm{C}$ (annealing) for $45 \mathrm{~s}$, and $72{ }^{\circ} \mathrm{C}$ (extension) for $90 \mathrm{~s}$; and a final extension of $72{ }^{\circ} \mathrm{C}$ for $10 \mathrm{~min}$. The secondary PCR products were visualized by $1.5 \%$ agarose gel electrophoresis. 
Table 1. Cryptosporidium xiaoi subtype families identified in sheep and goats in China.

\begin{tabular}{|c|c|c|c|c|c|c|c|c|}
\hline \multirow[t]{2}{*}{ Host } & \multirow[t]{2}{*}{ Region } & \multirow[t]{2}{*}{ Breed } & \multirow[t]{2}{*}{ Farm ID } & \multirow{2}{*}{$\begin{array}{l}\text { No. of } C \text {. xiaoi-Positive } \\
\text { Samples }\end{array}$} & \multirow{2}{*}{$\begin{array}{c}\text { No. of Samples } \\
\text { Positive at the gp60 } \\
\text { Locus (\%) }\end{array}$} & \multicolumn{2}{|c|}{$\begin{array}{l}\text { No. of Samples with } \\
\text { Divergent } g p 60 \text { PCR } \\
\text { Banding Patterns (\%) }\end{array}$} & \multirow[t]{2}{*}{ Subtype Family (no.) } \\
\hline & & & & & & One Band & Two Bands & \\
\hline \multirow{5}{*}{ Sheep } & \multirow[t]{3}{*}{ Henan } & \multirow[t]{2}{*}{ Han } & 1 & 71 & $58(81.7)$ & $49(84.5)$ & $9(15.5)$ & \multirow{5}{*}{$\begin{array}{c}\text { XXIIIb (13), XXIIId (3), XXIIIf (1), XXIIIh (13), } \\
\text { XXIIIl (22), XXIIId + XXIIIk (1), XXIIId + XXIIIl (1) } \\
\text { XXIIIb (1), XXIIIf (1), XXIIIk (5), XXIIIl (3) } \\
\text { XXIIIb (8), XXIIIe (2), XXIIIf (1), XXIIIh (17), } \\
\text { XXIIIk (3), XXIIIl (17), XXIIIh + XXIIIk (2), XXIIIb + } \\
\text { XXIIIk (1), XXIIId + XXIIIl (1) } \\
\text { XXIIId (1), XXIIIe (1), XXIIIh (1), XXIIII (3) }\end{array}$} \\
\hline & & & 2 & 18 & $18(100.0)$ & $18(100.0)$ & - & \\
\hline & & & & & & & & \\
\hline & Anhui & $\mathrm{Hu}$ & 3 & 84 & $64(76.2)$ & $57(89.0)$ & $7(11.0)$ & \\
\hline & Qinghai * & Tibetan & 4 & 39 & $8(20.5)$ & $8(100.0)$ & - & \\
\hline \multirow{7}{*}{ Goats } & \multirow[t]{2}{*}{ Anhui } & \multirow[t]{2}{*}{ Huanghuai } & 5 & 77 & $77(100.0)$ & $66(84.7)$ & $11(15.3)$ & $\begin{array}{c}\text { XXIIIa (6), XXIIIb (4), XXIIIc (1), XXIIId (2), XXIIIe } \\
\text { (5), XXIIIh (7), XXIIIi (4), XXIIIj (4), XXIIIk (5), } \\
\text { XXIIIl (18), XXIIIb + XXIIIl (1), XXIIIh + XXIIIi (1), } \\
\text { XXIIIh + XXIIIj (1), XXIIIh + XXIIIk (1), } \\
\text { XXIIII + XXIIIl (1) }\end{array}$ \\
\hline & & & 6 & 51 & $46(90.2)$ & $43(93.5)$ & $3(6.5)$ & $\begin{array}{c}\text { XXIIIb (3), XXIIIc (1), XXIIII (3), XXIIIIe (5), XXIIIf } \\
\text { (7), XXIIIh (4), XXIIII (3), XXIIIj (1), XXIIIk (7), } \\
\text { XXIIIl (4), XXIIIh +XXIIIk (1) }\end{array}$ \\
\hline & \multirow{5}{*}{ Guangdong } & \multirow{5}{*}{ Black } & 7 & 33 & $33(100.0)$ & $31(93.9)$ & $2(6.1)$ & XXIIIa (20), XXIIIg (5), XXIIIa + XXIIIg (1) \\
\hline & & & 8 & 20 & $16(80.0)$ & $16(100.0)$ & - & XXIIId (1), XXIIIg (14) \\
\hline & & & 9 & 11 & $8(72.7)$ & $8(100.0)$ & - & XXIIIa (8) \\
\hline & & & 10 & 18 & $16(88.9)$ & $16(100.0)$ & - & XXIIIa (16) \\
\hline & & & 11 & 12 & $11(91.7)$ & $11(100.0)$ & - & XXIIIa (11) \\
\hline Total & - & - & - & 434 & $355(81.8 \%)$ & $323(90.1)$ & $32(9.9)$ & $\begin{array}{c}\text { XXIIIa (61), XXIIIb (29), XXIIIc (2), XXIIId (10), } \\
\text { XXIIIe (13), XXIIIf (10), XXIIIg (19), XXIIIh (42), } \\
\text { XXIIII (10), XXIIIj (5), XXIIIk (20), XXIIIl (64), } \\
\text { XXIIIa + XXIIIg (1), XXIIIb + XXIIIk (1), XXIIIb + } \\
\text { XXIIII (1), XXIIId + XXIIIk (1), XXIIId + XXIIIl (2), } \\
\text { XXIIIh + XXIIIi (1), XXIIIh + XXIIIj (1), XXIIIh + } \\
\text { XXIIIk (4), XXIIIi + XXIIIl (1) }\end{array}$ \\
\hline
\end{tabular}




\subsection{DNA Sequence Analysis}

All secondary gp60 PCR products were sequenced in both directions using Sanger sequencing by Sangon Biotech (Shanghai, China). For the samples yielding double PCR bands with different sizes, PCR products of each band were excised from the agarose electrophoresis gel and purified using the E.Z.N.A. ${ }^{\circledR}$ Gel Extraction Kit (Omega bio-tek, Norcross, GA, USA) before sequencing. The sequences obtained were assembled using ChromasPro 1.5 (http: / / technelysium.com.au/wp/chromaspro/, accessed on 20 March 2020), edited using BioEdit 7.1 (http:/ / www. mbio.ncsu.edu/bioedit/bioedit, accessed on 20 March 2020), and aligned with reference sequences from GenBank using MUSCLE in MEGA 7.0 (https: / / www.megasoftware.net/, accessed on 20 March 2020). Short tandem repeats in the gene were identified using the Tandem Repeat Finder (http:/ / www.tandem.bu.edu/ trf/trf, accessed on 21 March 2020). The signal peptide and glycosylphosphatidylinositol (GPI) anchor were predicted using PSORT II (http:/ / psort.hgc.jp/ form2.html, accessed on 22 March 2020). N-glycosylated sites, O-glycosylated sites, and furin proteolytic cleavage sites were predicted using NetNGlyc 1.0 (http:/ / www.cbs.dtu.dk/services/NetNGlyc/, accessed on 22 March 2020), YinOYang 1.2 (http:/ / www.cbs.dtu.dk/services/YinOYang/, accessed on 22 March 2020), and ProP 1.0 (http:/ / www.cbs.dtu.dk/services/ProP/, accessed on 22 March 2020), respectively. To assess the genetic relationship of C. xiaoi subtype families, a phylogenetic tree was conducted using the maximum likelihood (ML) analysis in MEGA 7.0 based on substitution rates calculated with the general time-reversible model. DnaSP 5.10 (www.ub.es/dnasp/, accessed on 25 March 2020) was used to calculate the recombination rates among subtype families of $C$. xiaoi.

\subsection{Nucleotide Sequence Accession Numbers}

Representative nucleotide sequences of the C. xiaoi gp60 gene generated in this study were deposited in GenBank under accession numbers MW589389, MW815183-MW815276.

\section{Results}

\subsection{Features of the gp60 Gene of C. xiaoi}

A total of 25.85 million paired-end reads were obtained from the C. xiaoi isolate SCAU2942, and assembled into 334,080 contigs. The full gp60 gene (MW589389) was identified in contig 1122 (8944 bp). The gene was $1437 \mathrm{bp}$ in length and encoded 478 amino acids. Although it shared sequence similarities with the gp60 gene of C. parvum (AF022929), C. hominis (FJ839883), C. ubiquitum [12], and C. ryanae [17] in the $5^{\prime}$ and $3^{\prime}$ regions at the amino acid level, the full sequence similarity was only 19.9 to $41.6 \%$ between C. xiaoi and the other four species (Figure 1). The GP60 protein of C. xiaoi had classic features of Cryptosporidium GP60 proteins, including an N-terminal signal peptide, a furin cleavage site (RSRR), two potential N-glycosylation sites, nearly 100 O-glycosylation sites in the GP40 region, and a GPI anchor at the $C$ terminus. Nevertheless, the serine repeats (TCA/TCG/TCT) commonly seen in C. parvum, C. hominis, and related species, were absent in the $5^{\prime}$ region of the gp60 gene of $C$. xiaoi.

\subsection{Sequence Polymorphisms in the gp60 Gene of C. xiaoi}

Among the 434 samples positive for C. xiaoi in this study, the gp60 gene in 355 samples $(81.8 \%)$ was successfully amplified by PCR. PCR products of 323 samples generated one expected band in gel electrophoresis. However, 32 samples yielded two PCR bands with different sizes, including 16 sheep samples and 16 goat samples (Table 1 and Figure 2). All PCR products with either one or two bands were sequenced, generating 298 gp 60 nucleotide sequences with length ranging from 800 to $1170 \mathrm{bp}$. Nucleotide sequences from 18 samples were identical to the reference sequence (SCAU2942) from the whole-genome sequencing, while the remaining sequences were highly divergent and displayed nucleotide differences of 24.0-68.3\% (Table 2). Altogether, 94 sequence types were identified among the 298 gp60 sequences obtained. In addition to the numerous nucleotide substitutions observed over 
the partial gp60 gene, there was a significant length polymorphism among the 94 sequence types mostly due to the presence of repetitive sequences.

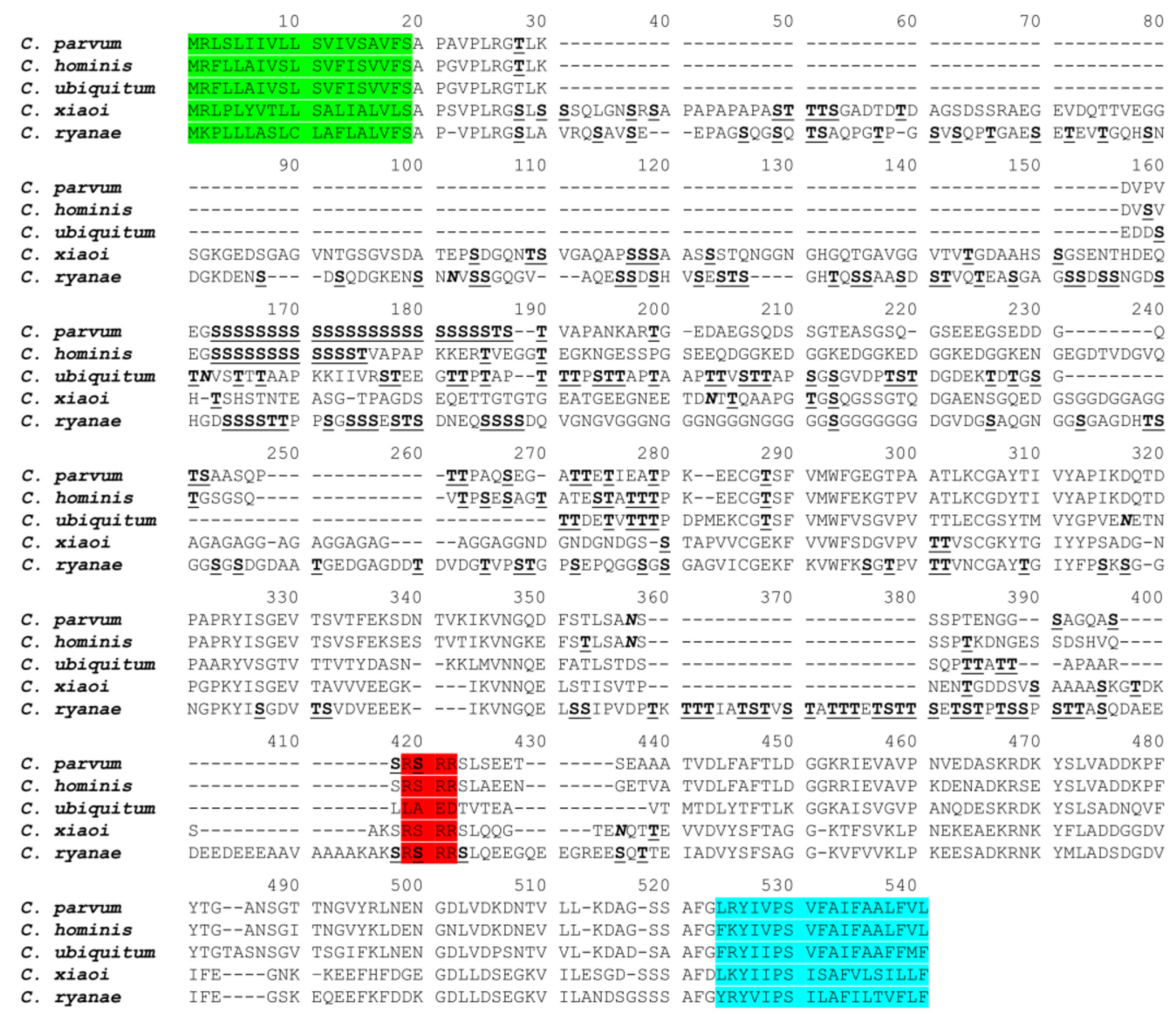

Figure 1. Deduced amino acid sequence of the gp60 gene of Cryptosporidium xiaoi compared with sequences of C. parvum (AF022929), C. hominis (FJ839883), C. ubiquitum [12], and C. ryanae [17]. Potential $\mathrm{N}$-glycosylation sites are indicated in bold and italic letters, and predicted O-glycosylation sites are indicated in bold and underlined letters. Amino acid sequences of the N-terminal signal peptide, furin cleavage site (RSRR), and C-terminal glycosylphosphatidylinositol anchor are highlighted in green, red, and blue, respectively. Dashes represent amino acid deletions.

Table 2. Pairwise nucleotide sequence similarity among subtype families of Cryptosporidium xiaoi in the gp60 gene.

\begin{tabular}{|c|c|c|c|c|c|c|c|c|c|c|c|c|}
\hline & XXIIIa & XXIIIb & XXIIIc & XXIIId & XXIIIe & XXIIIf & XXIIIg & XXIIIh & XXIIIi & XXIIIj & XXIIIK & XXIIII \\
\hline XXIIIa & & & & & & & & & & & & \\
\hline XXIIIb & $76.0 \%$ & & & & & & & & & & & \\
\hline XXIIII & $71.2 \%$ & $74.0 \%$ & & & & & & & & & & \\
\hline XXIIId & $70.1 \%$ & $72.7 \%$ & $68.8 \%$ & & & & & & & & & \\
\hline XXIIIe & $71.8 \%$ & $72.7 \%$ & $68.3 \%$ & $71.6 \%$ & & & & & & & & \\
\hline XXIIIf & $74.3 \%$ & $69.0 \%$ & $66.3 \%$ & $70.1 \%$ & $75.8 \%$ & & & & & & & \\
\hline XXIIIg & $68.3 \%$ & $66.2 \%$ & $66.0 \%$ & $66.4 \%$ & $69.8 \%$ & $71.4 \%$ & & & & & & \\
\hline XXIIIh & $54.1 \%$ & $56.0 \%$ & $50.4 \%$ & $55.0 \%$ & $56.4 \%$ & $57.1 \%$ & $57.6 \%$ & & & & & \\
\hline XXIIIi & $41.4 \%$ & $38.2 \%$ & $37.9 \%$ & $42.6 \%$ & $40.9 \%$ & $41.4 \%$ & $39.4 \%$ & $38.5 \%$ & & & & \\
\hline XXIIIj & $47.6 \%$ & $45.3 \%$ & $43.6 \%$ & $46.1 \%$ & $44.8 \%$ & $45.2 \%$ & $44.3 \%$ & $42.4 \%$ & $47.1 \%$ & & & \\
\hline XXIIIK & $37.9 \%$ & $35.7 \%$ & $35.5 \%$ & $37.3 \%$ & $37.9 \%$ & $39.4 \%$ & $37.6 \%$ & $34.7 \%$ & $49.8 \%$ & $50.5 \%$ & & \\
\hline XXIIIl & $33.9 \%$ & $31.7 \%$ & $32.2 \%$ & $35.4 \%$ & $33.6 \%$ & $35.3 \%$ & $33.9 \%$ & $31.8 \%$ & $42.3 \%$ & $42.5 \%$ & $58.3 \%$ & \\
\hline
\end{tabular}




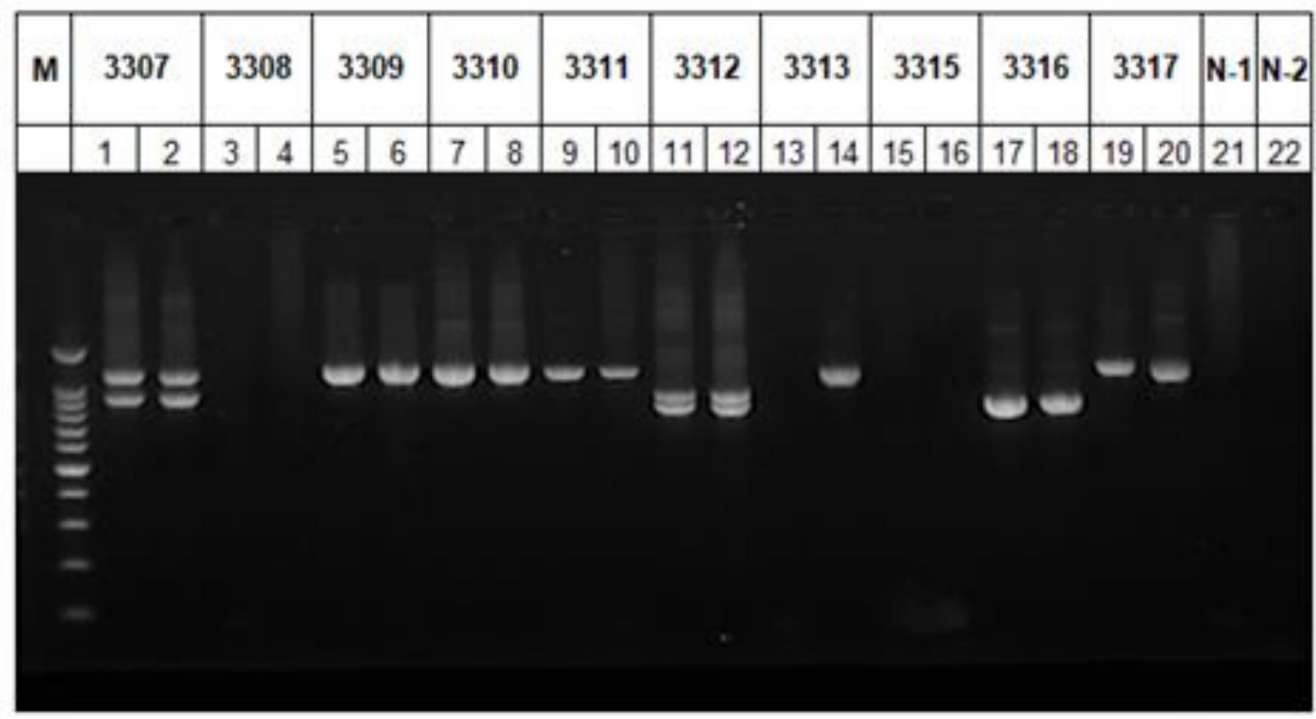

Figure 2. Nested PCR amplification of the partial gp60 gene of Cryptosporidium xiaoi in sheep and goat samples. M: 100-bp DNA ladder. Lanes 1-20: Replicate PCR of 10 samples with divergent binding patterns. N-1 and N-2: No-template controls in the primary and secondary PCR, respectively.

\subsection{Subtype Families and Subtypes of C.xiaoi}

A total of 94 gp 60 sequences, including one sequence of each sequence type, were used in a phylogenetic analysis of the gp60 gene. The ML tree generated comprised 12 clusters of sequences (Figure 3). They were named as subtype families XXIIIa-XXIIIl in concordance with the established nomenclature of gp60 subtype families of Cryptosporidium spp. [22]. Subtype families XXIIIa-XXIIIh formed a group highly divergent from the other group of XXIIII-XXIIIl (Figure 3). The nucleotide sequence differences among 12 subtype families ranged from 24.0 to $68.3 \%$ (Table 2). Among these subtype families, XXIIIl had the shortest nucleotide sequences and contained some unique AGC/AGT trinucleotide repeats encoding serine, leading to the occurrence of a long stretch of highly O-glycosylated amino acids. Subtypes within XXIIIl differed from each other mostly in the number of AGC/AGT trinucleotide repeats. The DnaSP analysis of the gp60 nucleotide sequences revealed the presence of 71 potential recombination events among all 12 subtype families (Table 2). In addition, mosaic sequence patterns were observed among these subtype families (Figure 4).

At the amino acid level, extensive sequence polymorphism was found among $12 \mathrm{sub}-$ type families, mostly in the GP40 region (Figure 4). Despite the extensive sequence difference, all subtype families had the furin cleavage site of RSRR. There were one to four $\mathrm{N}$-glycosylation sites in these subtype families, except for XXIIIk, which had none. In addition, the number of $\mathrm{O}$-glycosylation sites was divergent among subtype families, with XXIIIb and XXIIIl having more O-glycosylation sites than other subtype families. 


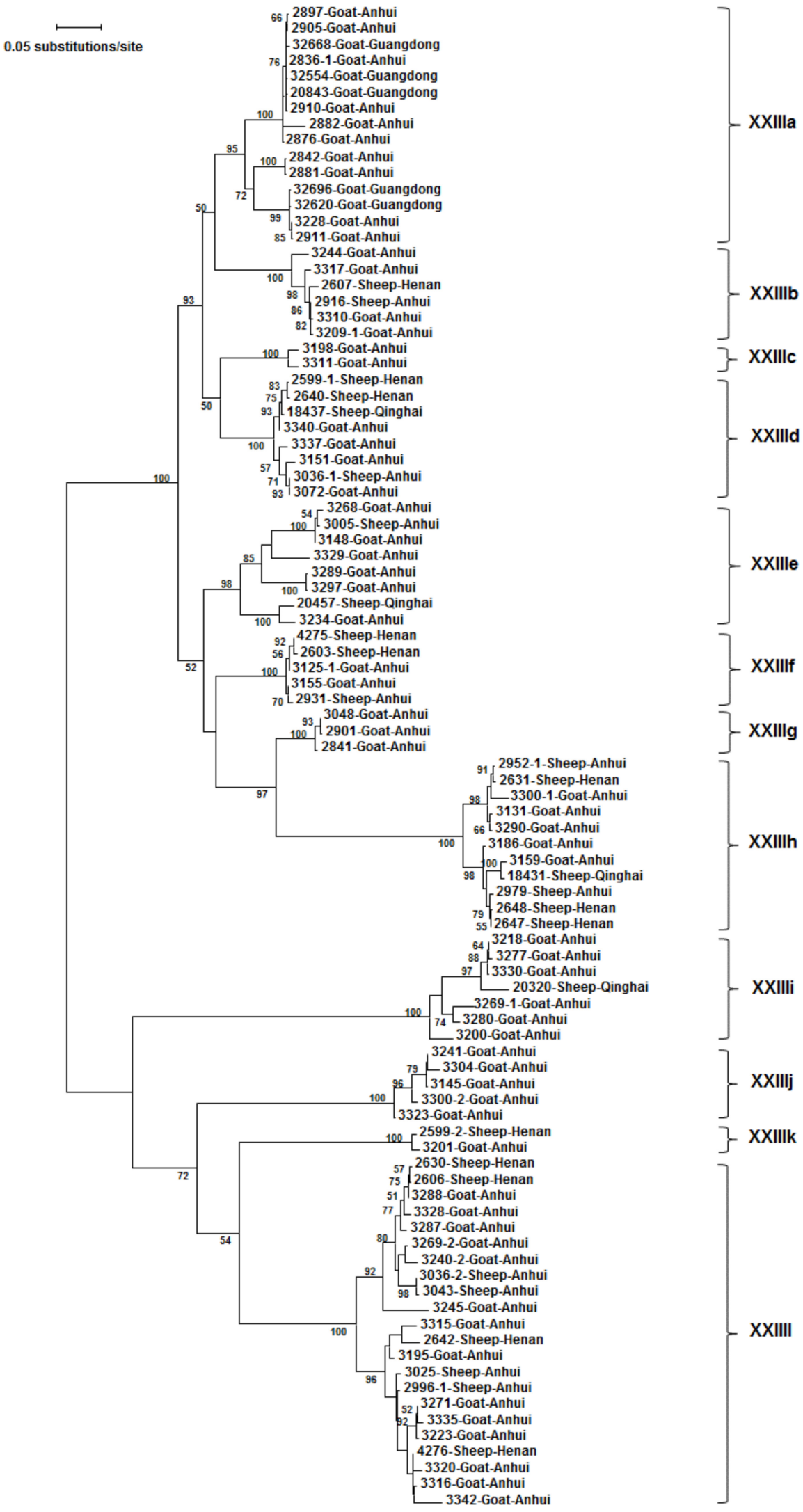

Figure 3. Phylogenetic relationship among 12 Cryptosporidium xiaoi subtype families (XXIIIa-XXIIIl) based on the maximum likelihood analysis of the partial gp60 gene. General time-reversible model and Gamma distribution were used in the calculation of substitution rates. Bootstrap values lower than $50 \%$ are not displayed. 


\section{XXIIIa-20843 XXIIIb-2607 XXIIIc-3198 XXIIId-2640 XXIIIe-3329 XXIIIf-2603 XXIIIg-3048 XXIIIh-2648 XXIIIi-3200 \\ XXIIIj-3145 XXIIIk-3201 XXIIII-4276}

XXIIIa-20843 XXIIIb-2607 XXIIIc-3198

XXIIId-2640 XXIIIe-3329 XXIIIf-2603 XXIIIg-3048 XXIIIh-2648

XXIIIi-3200 XXIIIj-3145 XXIIIk-3201 XXIIII-4276

XXIIIa-20843 XXIIIb-2607 XXIIIc-3198 XXIIId-2640 XXIIIe-3329 XXIIIf-2603 XXIIIg-3048 XXIIIh-2648 XXIIIi-3200 XXIIIj-3145 XXIIIk-3201 XXIIIl-4276

XXIIIa-20843 XXIIIb-2607 XXIIIC-3198 XXIIId-2640 XXIIIe-3329 XXIIIf-2603

XXIIIg-3048 XXIIIh-2648 XXIIIi-3200 XXIIIj-3145

XXIIIk-3201

XXIIII-4276

XXIIIa-20843 XXIIIb-2607 XXIIIc-3198 XXIIId-2640

XXIIIe-3329

XXIIIf-2603 XXIIIg-3048 XXIIIh-2648 XXIIIi-3200

XXIIIj-3145 XXIIIk-3201 XXIIII-4276

10 20 40 50

60 70 80 90 -GRSSV OPRDAPAEPG VEGSGENGEN GESEESEVKE KEEKEEKEEK PEEQVTTENS TSNTVQSSDS GNTV--TOTP SASTST-SQQ ----- -- - GVNGSSSV QRRDS---- --TETTESAV GGSEG--SEV EGQTEEQNTT E-DSSSSSSS SSTTVQSSNS GSTD--AQTS SSSAG--TQQ

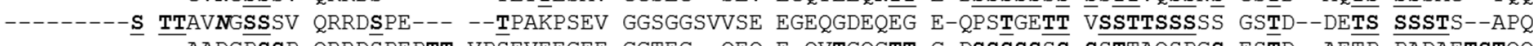

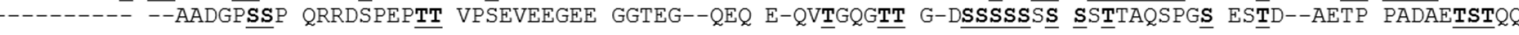
-----SSSS TTDVNGSGSV QRRDSTE--- --TTTEPSET SESAED---- EVEEQAEGQG TTEDSTS-TS TSSTVQSSGS ESTGSTQQTS STSTSA-SQQ --1--- --NGHSPV QPRDVPAESV VDGSGE---- --SEES---- KEGKEKAEE- -EGHVTTENG NSDSVQSDSG NEED--AQTS STGTVP-STQ ------ ----GRSSV QPRDSAA--- --TPTEETAA GGGVG---GE EGEQEEESKG EGEQASTVDG GSGTVQP

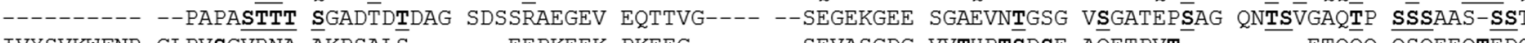
IVYSVKWFNR CLPV --- - - ---VHCLVPQ LGNSRSA--- ---PASDPSH EGDGV----- --ESTEAQEG DSONSTTHEG QQEQPETEVG AS---TTQST VTTGSSGNGD -------- $\underline{\mathbf{S}}$ TTTVNGHSSV QRRA STE--- ---STTDSGV SGEDV----- --ESTVAQEG A --

110

130

140

150

160

170

180

190

200

SNGETQNTGS TGSTTETPSS -TTSPPTSES TPGGEQESSS SAGT----- --------S DTDNQEHSTT -------- -------GG TGT----DGS DSGATQNTES TSSTGETTAS STTSPSSSES TSDGQQTSST TAVTSTQQGS GGAHT

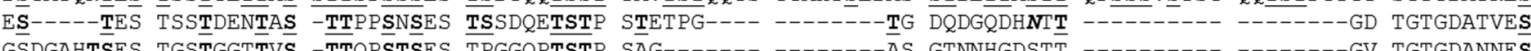
GSDGAHTSES TGSTGGTTVS -TTQPSTSES TPGGQPTSTP SÄG--.--_ SNSETHSTES TGSTSETĀSS -TTSPSSSES TTNGEQTSST STEASS--.- - QGDGEQNTEV SDSTSETASS -TTPPSSSES TTGGEQTSAP SAGT--

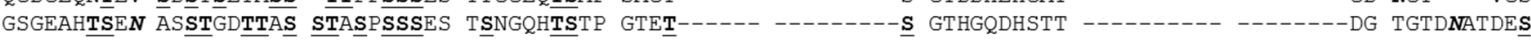

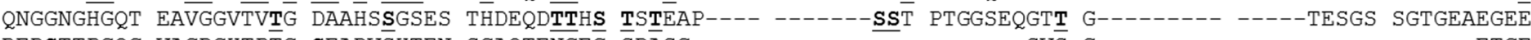
REDSTTPGQG VAGDGHTPTG SEADVSHTEN SGAQTENGEG SDASG-_-n NSGTVDSNHS TSADSTSQPT GSGSGTTTES GSGEDDVEAG SSTS---1-- - A SSSSSSTSTS TSATSSS-- -

210

GNN-TDHTDS S SGATEADST EGDDTTIDSNT HGTTTPG EST-TDH-VS SGTSTEADST EGGDT GST-TGN-- --TGSGAGS- AGGGSTNSGA QEGTTTETGS QGSSTDGS-A NGDSQGG--S GSGG-----A GAGNDGS-TA GIVCGEEFTI WFS-GGVPVT EST-TDHDAS SGTSTNTGSE EGGDTTDGNT QEGTTPGSGS PGSSTNGS-D NGNGQE---S GSSG----S GAGNGGS-TA GIVCGEEFTI WFDSGAIPVT GSG-TGETE- -------GE EGNEQTDTT- --QAA GST-TDHTG- SGTG----ST EGGDATDSDS QDGTTTGSGS HGSSTNGG-G NGNGQGSG-S GGAG-----A GAGNDGSTT PVICGEKFVV WFSDG-IPVT

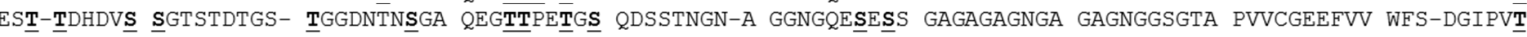
GNGETDTTQA AGTG----SQ GSSGTQDGTE NNGQENGSGG AGGPGPGAGA GGAGAG--- GAGG-----N DGGNDGSSTA PVICGEKFVV WFSDG-VPVT HNGTTGDNAH DQTNNSGVHT DAESSTGSST GSSTSSDAVT NQGGDQSDVS TGAGSTTDGS GSGS------ ---HDAPGSP TVVCGEKFTI WFSGG-VPVT

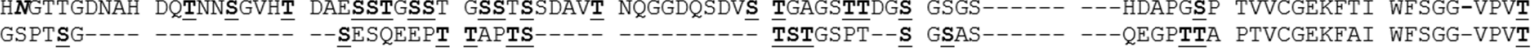

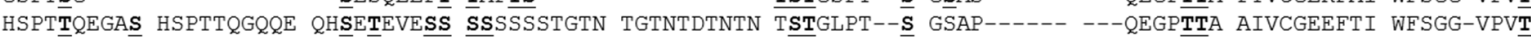
$\underline{\text { S }}$ STSTS--..

310

320

330

340

350

360

370

380

390

TVSCGDYTI YYPSAGNS TVDCGPYTGI YYPAIGGNSE PKYISGEVTS VDVTDDKIKV NGHDLSSIPV N

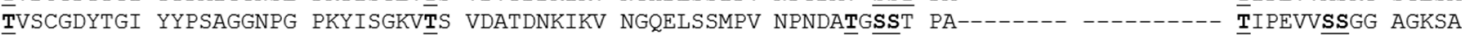

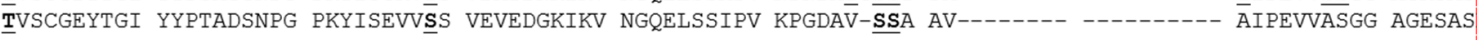
TVSCGEYTGI YYPSANGNPG PKYISGGVTS VEVEDGKIKV NGEELSSIPV KPGDAASS TVSCGDYTGI YYPSAGGNPG PKYITGGVDS VEVKDGKIMV NDHELSSIPV NPGDPV-SST PV------- -------- TIPELVASED SGKSGS

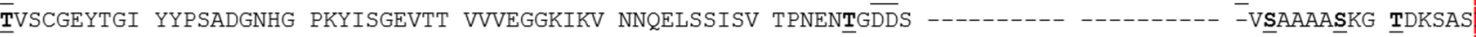

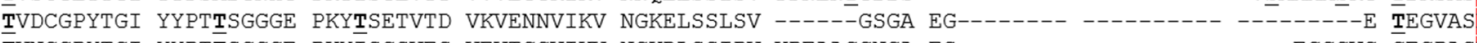
TVNCGPYTGI YYPT TISGGGE PKYISGSVES VEVTGGVIKV NGKDLSSIPV KPEAAGGNGA ES-------- --------- ----EGGGVG GEGPAS TVDCGPYTGI YYPAIDGNSE PKYISGKVTS VDVTDNIIKV NNQELSSIPV KPEAPGGSGA ESGAGAGAGA GAGGGGGAGV DGGEEGGEEG GEVTAS

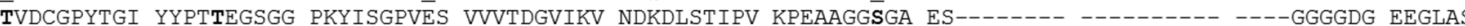
420 430 440 $450 \quad 454$

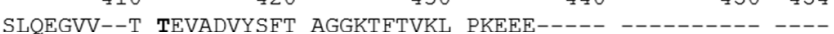
SLQEEVV--T TEVADAYSFS AGGRVFTVKL PKETEAS--- - - - - - - - -- ---

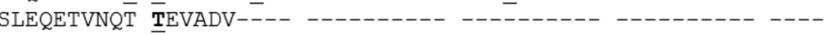

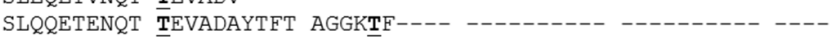
SLQEEVV--T TEVADVYSFS AGGKVFTVKL PKETEA---- --------- ---SLOEEVV--T TEVADVYSFT AGGKSFTVKL PKEEEAS--- - - - - - - - - - -

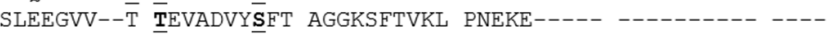
SLQQGTEDQT TEVVDVYSTT AGGKTFSVRL PNE------- --------- ---SLQEEVV--T TEVADVYSFT AGGKTFTVKL PKEADEKKRN KYFLADD--- --SLODVET- $-V$ AQIVDAYSFT ADGKTFVVKL PKEADEEKRN KYFLADDGGD VIF-

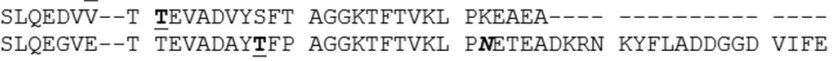

Figure 4. Deduced amino acid sequences of the partial gp60 gene of 12 subtype families (XXIIIa-XXIIIl) in Cryptosporidium xiaoi. N-glycosylation sites are indicated in bold and italic letters, and O-glycosylation sites are indicated in bold and underlined letters. The furin cleavage site "RSRR" is highlighted in red. Dashes represent amino acid deletions (except those at both ends of the sequences). 


\subsection{Distribution of C. xiaoi Subtype Families by Host}

Among the 12 subtype families of C. xiaoi, XXIIIa (61), XXIIIc (2), XXIIIg (19), and XXIIIj (5) were detected only in goats, while the remaining eight subtype families were found in both sheep and goats. In addition, a common occurrence of co-infections with multiple subtype families was observed in these animals. Among the three breeds of sheep, 64 samples from Han sheep were successfully subtyped, yielding XXIIIb (14), XXIIId (3), XXIIIf (2), XXIIIh (13), XXIIIk (5), XXIIIl (25), XXIIId + XXIIIk (1), and XXIIId + XXIIIl (1); 52 samples from Hu sheep were successfully subtyped, yielding XXIIIb (8), XXIIIe (2), XXIIIf (1), XXIIIh (17), XXIIIk (3), XXIIIl (17), XXIIIh + XXIIIk (2), XXIIIb + XXIIIk, (1) and XXIIId + XXIIIl (1); only a few samples from Tibetan sheep were successfully subtyped, yielding XXIIId (1), XXIIIe (1), XXIIIh (1), and XXIIIi (3). Between the two breeds of goats, only XXIIIa was identified in Black goats, while more divergent subtype families were detected in Huanghuai goats, yielding XXIIIa (26), XXIIIb (7), XXIIIc (2), XXIIId (6), XXIIIe (10), XXIIIf (7), XXIIIg (19), XXIIIh (11), XXIIIi (7), XXIIIj (5), XXIIIk (12), and XXIIIl (22). Noticeably, co-infections of various subtype families were detected in Huanghuai goats, including XXIIIa + XXIIIg (1), XXIIIb + XXIIII (1), XXIIIh + XXIIIi (1), XXIIIh + XXIIIj (1), XXIIIh + XXIIIk (2), and XXIIIi + XXIIIl (1) (Table 1).

\subsection{Distribution of C. xiaoi Subtype Families by Farm}

One to 10 subtype families were found on each farm. As shown in Table 1, three farms had only one subtype family, two farms had two, two farms had four, one farm had six, one farm had seven, and two farms had 10. On Farms 9, 10, and 11 in Guangdong, all gp60 sequences obtained belonged to the subtype family XXIIIa. In contrast, although only eight samples were subtyped on Farm 4 in Qinghai, they belonged to four subtype families (XXIIId, XXIIIe, XXIIIh, and XXIIIi). In addition, co-infections of different subtype families were observed in animals on Farms 1, 3, 5, 6, and 7, mostly with prevalent subtype families on the farm (Table 1).

\section{Discussion}

In the present study, we conducted whole genome sequencing of C. xiaoi and identified its $g p 60$ gene. Based on the sequence data, we established a gp60-based subtyping tool to assess the genetic diversity of C. xiaoi. The application of this subtyping tool in the analysis of C. xiaoi-positive samples from various breeds of sheep and goats has identified high genetic diversity within the species and possible differences in the distribution of subtypes between the two types of hosts.

The gp60 gene sequence of $C$. xiaoi is highly divergent from that of other Cryptosporidium spp. Similar to the gp60 gene of C. ryanae ( 1548 bp), the C. xiaoi gp60 gene ( $1437 \mathrm{bp})$ is much longer than those in C. parvum, C. hominis, and C. ubiquitum ( 873-1035 bp). Both the nucleotide and amino acid sequences of the C. xiaoi gp60 gene showed low identity to those of other Cryptosporidium spp. This may explain the inability of the commonly used gp60 primers to amplify DNA of C. xiaoi [23]. Similar to C. ubiquitum, C. canis, C. felis, and C. ryanae, the trinucleotide repeats of TCA/TCG/TCT encoding a polyserine tract at the $5^{\prime}$ end of the gp60 gene and widely used to differentiate subtypes within subtype families, were absent in the gp60 sequence of $C$. xiaoi $[12,13,17,24]$. However, a polyserine tract encoded by AGC/AGT repeats was observed in the gp60 gene of the subtype family XXIIIl, and subtypes within XXIIIl differed mostly in the number of AGC/AGT repeats. Similar to most Cryptosporidium spp., the GP60 protein of C. xiaoi has a classic furin cleavage site "RSRR" between GP40 and GP15, which is absent in C. ubiquitum, C. viatorum, Cryptosporidium chipmunk genotype I and skunk genotype $[9,11,12,14]$.

Based on the sequence analysis, the gp60 gene of C. xiaoi displays an extremely high genetic diversity. The analysis of 298 sequences obtained led to the identification of 94 sequence types in 12 subtype families, including significant length polymorphism and sequence variability. The high sequence heterogeneity in this gene, nevertheless, has made PCR amplification difficult, which together with the large amplicon could 
be responsible for the poor amplification efficiency. In addition, some samples (13/355) produced double bands in gp60 PCR, indicating the presence of concurrent infection with different subtypes in sheep and goats. This may facilitate the occurrence of genetic recombination among C. xiaoi subtypes, illustrated by the identification of mosaic sequence patterns and 71 potential recombination events in the overall sequence data. Thus, genetic recombination might be responsible for high sequence heterogeneity in the gp60 gene of C. xiaoi. Genetic recombination at the gp60 locus was observed in C. parvum, C. hominis, C. ubiquitum, and C. ryanae $[2,12,17]$.

The gp60 subtyping results suggest the presence of host adaptation within C. xiaoi. Among the 12 subtype families, XXIIIa, XXIIIc, XXIIIg, and XXIIIj were observed only in goats thus far. For the two breeds of goats, Huanghuai goats in Anhui harboured all subtype families of XXIIIa-XXIIIl. In contrast, all 35 samples from Black goats in Guangdong belonged to XXIIIa. The latter could be due to the reduced genetic diversity of C. xiaoi in the province. Previously, host-adapted gp60 subtype families had been identified in other Cryptosporidium spp., such as C. paroum, C. hominis, C. felis, C. ubiquitum, C. tyzzeri, and C. ryanae $[2,12,17,25-27]$.

No obvious correlation was found between the distribution of C. xiaoi subtype families and geographic locations in this study. Even though all C. xiaoi isolates from three farms in Guangdong belonged to XXIIIa, this subtype family was found in goats on two farms in Anhui. Subtyping data of $C$. xiaoi from more geographic locations and diverse animals are needed for better understanding of the distribution of C. xiaoi subtypes. Previously, geographical differences had been reported in the subtype distribution of $C$. hominis, C. paroum, C. felis, C. ubiquitum, C. ryanae, and Cryptosporidium chipmunk genotype I, indicating possible differences in the transmission of these pathogens $[9,12,17,25,27,28]$.

\section{Conclusions}

In the present study, we conducted whole-genome sequencing of C. xiaoi and developed a subtyping tool based on the gp60 gene. The application of this new tool in the analysis of fecal samples from sheep and goats has revealed a high genetic diversity within the species, and likely identified the occurrence of host adaptation at the subtype family level. Further studies with extensive sampling of various hosts in diverse areas are needed to improve our understanding of the transmission characteristics of C. xiaoi.

Author Contributions: L.X. and N.L. conceived and designed the experiments; Y.F. (Yingying Fan), X.H. and S.G. performed the experiments; F.Y. X.Y., Y.G. and Y.F. (Yaoyu Feng) provided technical assistance; Y.F. (Yingying Fan), L.X. and N.L. analyzed the data; Y.F. (Yingying Fan), L.X. and N.L. wrote the paper. All authors have read and agreed to the published version of the manuscript.

Funding: National Natural Science Foundation of China (U1901208 and 32030109), 111 Project (D20008), and Innovation Team Project of Guangdong University (2019KCXTD001).

Institutional Review Board Statement: Not applicable.

Informed Consent Statement: Not applicable.

Data Availability Statement: Data is contained within the article.

Conflicts of Interest: The authors declare no conflict of interest.

\section{References}

1. Kotloff, K.L. The burden and etiology of diarrheal illness in developing countries. Pediatr. Clin. N. Am. 2017, 64, 799-814. [CrossRef]

2. Feng, Y.; Ryan, U.M.; Xiao, L. Genetic diversity and population structure of Cryptosporidium. Trends Parasitol. 2018, 34, 997-1011. [CrossRef]

3. Feng, Y.; Xiao, L. Molecular epidemiology of cryptosporidiosis in China. Front. Microbiol. 2017, 8, 1701. [CrossRef] [PubMed]

4. Fayer, R.; Santin, M. Cryptosporidium xiaoi n. sp. (Apicomplexa: Cryptosporidiidae) in sheep (Ovis aries). Vet. Parasitol. 2009, 164, 192-200. [CrossRef] [PubMed]

5. Kaupke, A.; Michalski, M.M.; Rzezutka, A. Diversity of Cryptosporidium species occurring in sheep and goat breeds reared in Poland. Parasitol. Res. 2017, 116, 871-879. [CrossRef] [PubMed] 
6. Yang, R.; Jacobson, C.; Gardner, G.; Carmichael, I.; Campbell, A.J.; Ng-Hublin, J.; Ryan, U. Longitudinal prevalence, oocyst shedding and molecular characterisation of Cryptosporidium species in sheep across four states in Australia. Vet. Parasitol. 2014, 200, 50-58. [CrossRef]

7. Parsons, M.B.; Travis, D.; Lonsdorf, E.V.; Lipende, I.; Roellig, D.M.; Kamenya, S.; Zhang, H.; Xiao, L.; Gillespie, T.R. Epidemiology and molecular characterization of Cryptosporidium spp. in humans, wild primates, and domesticated animals in the Greater Gombe Ecosystem, Tanzania. PLoS Negl. Trop. Dis. 2015, 9, e0003529. [CrossRef] [PubMed]

8. Mi, R.; Wang, X.; Huang, Y.; Zhou, P.; Liu, Y.; Chen, Y.; Chen, J.; Zhu, W.; Chen, Z. Prevalence and molecular characterization of Cryptosporidium in goats across four provincial level areas in China. PLoS ONE 2014, 9, e111164. [CrossRef]

9. Guo, Y.; Cebelinski, E.; Matusevich, C.; Alderisio, K.A.; Lebbad, M.; McEvoy, J.; Roellig, D.M.; Yang, C.; Feng, Y.; Xiao, L. Subtyping novel zoonotic pathogen Cryptosporidium chipmunk genotype I. J. Clin. Microbiol. 2015, 53, 1648-1654. [CrossRef]

10. Stensvold, C.R.; Beser, J.; Axen, C.; Lebbad, M. High applicability of a novel method for gp60-based subtyping of Cryptosporidium meleagridis. J. Clin. Microbiol. 2014, 52, 2311-2319. [CrossRef]

11. Yan, W.; Alderisio, K.; Roellig, D.M.; Elwin, K.; Chalmers, R.M.; Yang, F.; Wang, Y.; Feng, Y.; Xiao, L. Subtype analysis of zoonotic pathogen Cryptosporidium skunk genotype. Infect. Genet. Evol. 2017, 55, 20-25. [CrossRef] [PubMed]

12. Li, N.; Xiao, L.; Alderisio, K.; Elwin, K.; Cebelinski, E.; Chalmers, R.; Santin, M.; Fayer, R.; Kvac, M.; Ryan, U.; et al. Subtyping Cryptosporidium ubiquitum, a zoonotic pathogen emerging in humans. Emerg. Infect. Dis. 2014, 20, 217-224. [CrossRef]

13. Rojas-Lopez, L.; Elwin, K.; Chalmers, R.M.; Enemark, H.L.; Beser, J.; Troell, K. Development of a gp60-subtyping method for Cryptosporidium felis. Parasites Vectors 2020, 13, 39. [CrossRef] [PubMed]

14. Stensvold, C.R.; Elwin, K.; Winiecka-Krusnell, J.; Chalmers, R.M.; Xiao, L.; Lebbad, M. Development and application of a gp60-based typing assay for Cryptosporidium viatorum. J. Clin. Microbiol. 2015, 53, 1891-1897. [CrossRef] [PubMed]

15. Rahmouni, I.; Essid, R.; Aoun, K.; Bouratbine, A. Glycoprotein 60 diversity in Cryptosporidium parvum causing human and cattle cryptosporidiosis in the rural region of Northern Tunisia. Am. J. Trop. Med. Hyg. 2014, 90, 346-350. [CrossRef] [PubMed]

16. Power, M.L.; Cheung-Kwok-Sang, C.; Slade, M.; Williamson, S. Cryptosporidium fayeri: Diversity within the gp60 locus of isolates from different marsupial hosts. Exp. Parasitol. 2009, 121, 219-223. [CrossRef]

17. Yang, X.; Huang, N.; Jiang, W.; Wang, X.; Li, N.; Guo, Y.; Kváč, M.; Feng, Y.; Xiao, L. Subtyping Cryptosporidium ryanae: A common pathogen in bovine animals. Microorganisms 2020, 8, 1107. [CrossRef] [PubMed]

18. Adamu, H.; Petros, B.; Zhang, G.; Kassa, H.; Amer, S.; Ye, J.; Feng, Y.; Xiao, L. Distribution and clinical manifestations of Cryptosporidium species and subtypes in HIV/AIDS patients in Ethiopia. PLoS Negl. Trop. Dis. 2014, 8, e2831. [CrossRef]

19. Li, P.; Cai, J.; Cai, M.; Wu, W.; Li, C.; Lei, M.; Xu, H.; Feng, L.; Ma, J.; Feng, Y.; et al. Distribution of Cryptosporidium species in Tibetan sheep and yaks in Qinghai, China. Vet. Parasitol. 2016, 215, 58-62. [CrossRef]

20. Xiao, L.; Escalante, L.; Yang, C.; Sulaiman, I.; Escalante, A.A.; Montali, R.J.; Fayer, R.; Lal, A.A. Phylogenetic analysis of Cryptosporidium parasites based on the small-subunit rRNA gene locus. Appl. Environ. Microbiol. 1999, 65, 1578-1583. [CrossRef]

21. Guo, Y.; Li, N.; Lysen, C.; Frace, M.; Tang, K.; Sammons, S.; Roellig, D.M.; Feng, Y.; Xiao, L. Isolation and enrichment of Cryptosporidium DNA and verification of DNA purity for whole genome sequencing. J. Clin. Microbiol. 2015, 53, 641-647. [CrossRef]

22. Xiao, L.; Feng, Y. Molecular epidemiologic tools for waterborne pathogens Cryptosporidium spp. and Giardia duodenalis. Food Waterborne Parasitol. 2017, 8-9, 14-32. [CrossRef] [PubMed]

23. Feng, Y.; Lal, A.A.; Li, N.; Xiao, L. Subtypes of Cryptosporidium spp. in mice and other small mammals. Exp. Parasitol. 2011, 127, 238-242. [CrossRef]

24. Jiang, W.; Roellig, D.M.; Guo, Y.; Li, N.; Feng, Y.; Xiao, L. Development of a subtyping tool for zoonotic pathogen Cryptosporidium canis. J. Clin. Microbiol. 2020, 59, e02474-20. [CrossRef]

25. Xiao, L. Molecular epidemiology of cryptosporidiosis: An update. Exp. Parasitol. 2010, 124, 80-89. [CrossRef] [PubMed]

26. Kváč, M.; McEvoy, J.; Loudová, M.; Stenger, B.; Sak, B.; Květoňová, D.; Ditrich, O.; Rašková, V.; Moriarty, E.; Rost, M.; et al. Coevolution of Cryptosporidium tyzzeri and the house mouse (Mus musculus). Int. J. Parasitol. 2013, 43, 805-817. [CrossRef] [PubMed]

27. Jiang, W.; Roellig, D.M.; Lebbad, M.; Beser, J.; Troell, K.; Guo, Y.Q.; Li, N.; Xiao, L.H.; Feng, Y.Y. Subtype distribution of zoonotic pathogen Cryptosporidium felis in humans and animals in several countries. Emerg. Microbes Infect. 2020, 9, $2446-2454$. [CrossRef] [PubMed]

28. Caccio, S.M.; de Waele, V.; Widmer, G. Geographical segregation of Cryptosporidium parvum multilocus genotypes in Europe. Infect. Genet. Evol. 2015, 31, 245-249. [CrossRef] 